\title{
A Sudanese Female Case with Rheumatoid Arthritis and Bronchiectasis as a Presentation and Low Vitamin D Level
}

\author{
Mohammed Elmujtba Adam Essa ${ }^{1,2 *}$, Ziryab Imad Taha ${ }^{1,3,7}$, Asaad Tageldein Idris Abdelhalim ${ }^{4}$, \\ Mohey Aldein Ahmed Elamin Elnour ${ }^{5}$, Almigdad HM Alii, Nuha Mohamed Ahmed Musa ${ }^{7}$, Asma \\ Elhaj Ibrahim Abdulgadir ${ }^{8}$ and Abdelkareem A Ahmed ${ }^{9,10}$
}

${ }^{1}$ Department of Clinical Medicine, Medical and Cancer Research Institute (MCRI), Sudan

${ }^{2}$ Faculty of Medicine, Alfashir University, Sudan

${ }^{3}$ Department of Internal Medicine, Faculty of Medicine, University of Bahri, Sudan

${ }^{4}$ Department of clinical Immunology, Sudan Medical Specialization Counsel, Sudan

${ }^{5}$ Faculty of Medicine, Omdurman Islamic University, Sudan

${ }^{6}$ Faculty of Medicine, University of Khartoum, Sudan

${ }^{7}$ Department of Internal Medicine and Rheumatology, Haj Alsafi Teaching hospital, Sudan

${ }^{8}$ Department of Respiratory Medicine, Alshaab Teaching hospital, Sudan

${ }^{9}$ Institute of Molecular Biology, University of Nyala, Sudan

${ }^{10}$ Department of Physiology and Biochemistry, Faculty of Veterinary Science, University of Nyala, Sudan

*Corresponding author: Mohammed Elmujtba Adam Essa, Department of Clinical Medicine, Medical and Cancer Research

Institute, Nyala, Sudan

\section{ARTICLE INFO}

Received: 㓞 January 19, 2021

Published: 彗 January 26, 2021

Citation: Mohammed Elmujtba Adam Essa, Ziryab Imad Taha, Asaad Tageldein Idris Abdelhalim, Mohey Aldein Ahmed Elamin Elnour, et al. A Sudanese Female Case with Rheumatoid Arthritis and Bronchiectasis as a Presentation and Low Vitamin D Level. Biomed J Sci \& Tech Res 33(3)-2021. BJSTR. MS.ID.005394.

\begin{abstract}
Rheumatoid arthritis (RA) is a common autoimmune multi-systemic inflammatory disease affecting joints result in dysfunction and ultimately damage. Bronchiectasis (BR) is a long-term pulmonary condition that is characterized by permanent dilation of the bronchial, the association of RA and BR has been recognized since the past five decades. This is the first reported document arthropathy in a female patient with bronchiectasis in Sudan. We aim to bring attention to the uncommon presentations and challenge of diagnosing patients of BR with RA. We are presenting 48 years old female complaining of chronic cough, chest pain and multiple joints pain. examination showed Tender joints, Z-shape thumbs appearance figure and hyper flexed DIP deformity in index fingers. chest auscultation reveals bilateral Coarse crackles disappears after coughing. Chest CT scan showed features suggested the diagnosis of BR, Anti-ccp positive, rheumatoid factor IgM, all indicate a diagnosis of RA in addition, the patient has low serum Vitamin D. Patient received hydroxychloroquine, Mycophenolate mofetil, vitamin D and calcium supplements and her general condition is improved.
\end{abstract}

Keywords: Rheumatoid arthritis; Bronchiectasis; low vitamin D; Mycophenolate mofetil

\section{Introduction}

RA is a common autoimmune multi-systemic inflammatory disease affecting joints result in dysfunction and ultimately damage. It is affecting $1-2 \%$ of the population worldwide [1]. The disease has a remarkable effect on women more than men by two to three-time [2]. It also has an extra-articular manifestation which may affect other system and organs such as eye, skin, vasculitis, cardiovascular and pulmonary disease. Development of this feature may a indicate high risk of morbidity and premature death [3], 
pulmonary involvement is unfrequented and difficult to detect clinically, hence the pleural disease is common but asymptomatic, studies reporting involvement in $50 \%$ of cases with $10 \%$ detection [4], also RA has been known to be a cause of BE in the prevalence of $3 \%$ in RA cohort [5]. In Sudan a lot of cases have been misdiagnosed due to low recognition of the disease in its early stage. This case report is the first one to document arthropathy in a female patient with bronchiectasis as presentation in Sudan. We believe that it will focus doctors' attention on the uncommon presentations and challenge of diagnosing patients with bronchiectasis.

\section{Case Presentation}

We are reporting a case of 48 years old female primary school teacher, with 5 children, married for 20 years, residents at Algaily at Khartoum north state, Sudan. Her medical history in the past is clear, had no smoking history, she was healthy and well until 3 years ago, she started to endure from a cough, which was lasting through all the day, productive with whitish small amount odourless sputum, not associated with fever or sweating, stationary in its course lasting for more than 4 months then she sought medical attention, as Sudan is a pandemic area for tuberculosis, initial workup for TB clinically and laboratory was done but clear and the investigation reveals no evidence of infection. Then she retained back again seeking for medical care at chest physician, the auscultation reveals Coarse crackles disappear after coughing on both sides of the chest at middle and lower zones, in addition to localized chest pain not radiated and associated with vomiting. He asked for furthermore workup, based on clinical features along with chest CT scan which showed there were bilateral septal thickening, ground-glass opacity mild bronchiectasis changes. he put his diagnosis as Bronchiectasis (Figure 1).

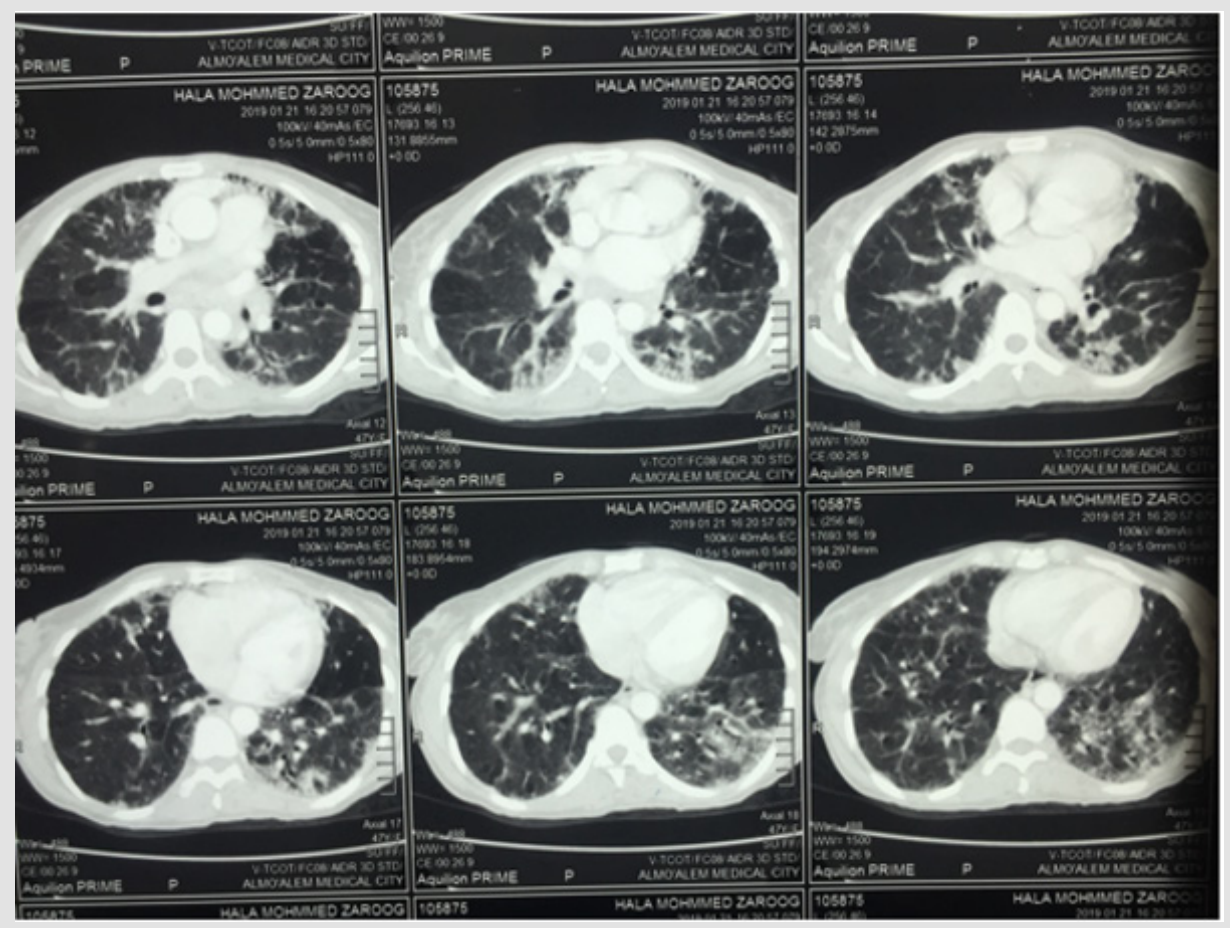

Figure 1: CT chest of the patient, shows bilateral septal thickening, ground-glass opacity mild bronchiectasis changes.

The patient has received antibiotics, prednisolone and cough syrup and her condition get improved. Ten months later after she received her treatment, the patient developed multiple joints pain including hands at metacarpophalangeal (MCP) joints, proximal interphalangeal (PIP) joints, Wrist joints, elbow joints, upper neck and lower back, knees and feet joints. It is often getting worse in the mornings and after she finished her ordinary daily activity, there is swelling mainly at small joints. The first episode was so severed but remitted spontaneously, after 6 months another episode appeared but less in the severity of the first attack and it affecting the same joints, after she asked medical attention again, the patient was referred to Rheumatologist, during examination patient showed
Tender MCP, PIP, Z-shape thumbs appearance Figure 2, hyperflexed deformity in index fingers (Figure 3), Full workup profile was done, investigation showed patient had Anti-ccp positive as well as rheumatoid factor IgM positive (Table 1), diagnosed with Rheumatoid Arthritis based on clinical manifestation and laboratory findings. Moreover, this patient has a remarkable vitamin D level deficiency. Patient received hydroxychloroquine $200 \mathrm{mg}$ BD, Mycophenolate mofitel acid $500 \mathrm{mg}$ tabs BD and calcium supplements, Vitamin D tab 50000 once per week for three months, symbicort inhaler and Vitaferrol Cap (iron tonics) daily for 3 months. The patient now in well condition and on regular follow up. 


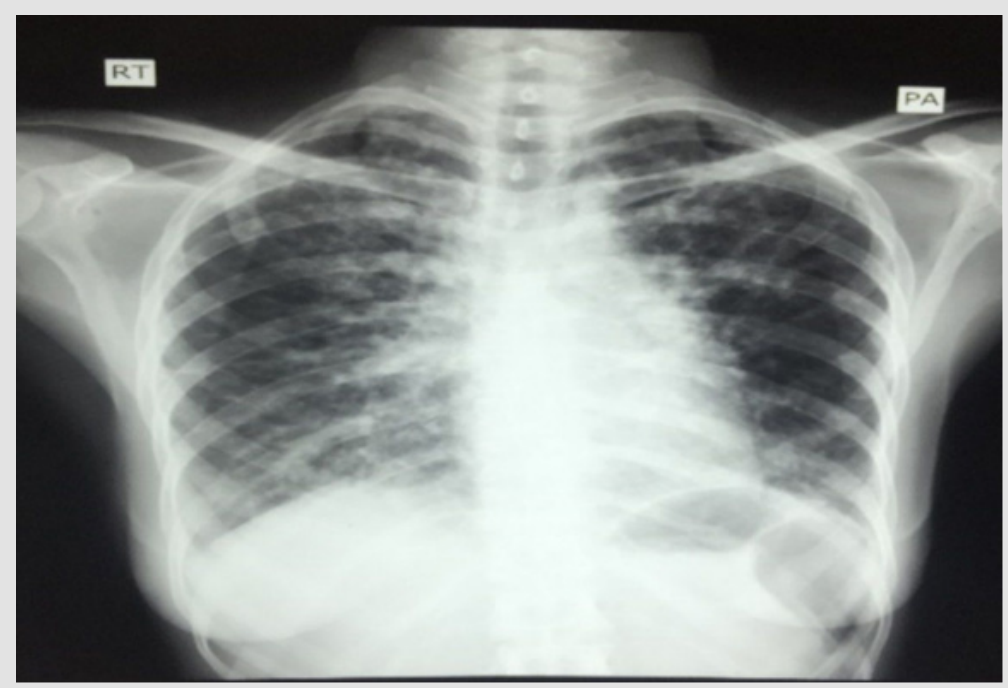

Figure 2: CXR Show: extensive reticulonodular shadowing with honey combing and cystic changes affecting both lung fields mid and upper zones with few changes seen in the lower zones.

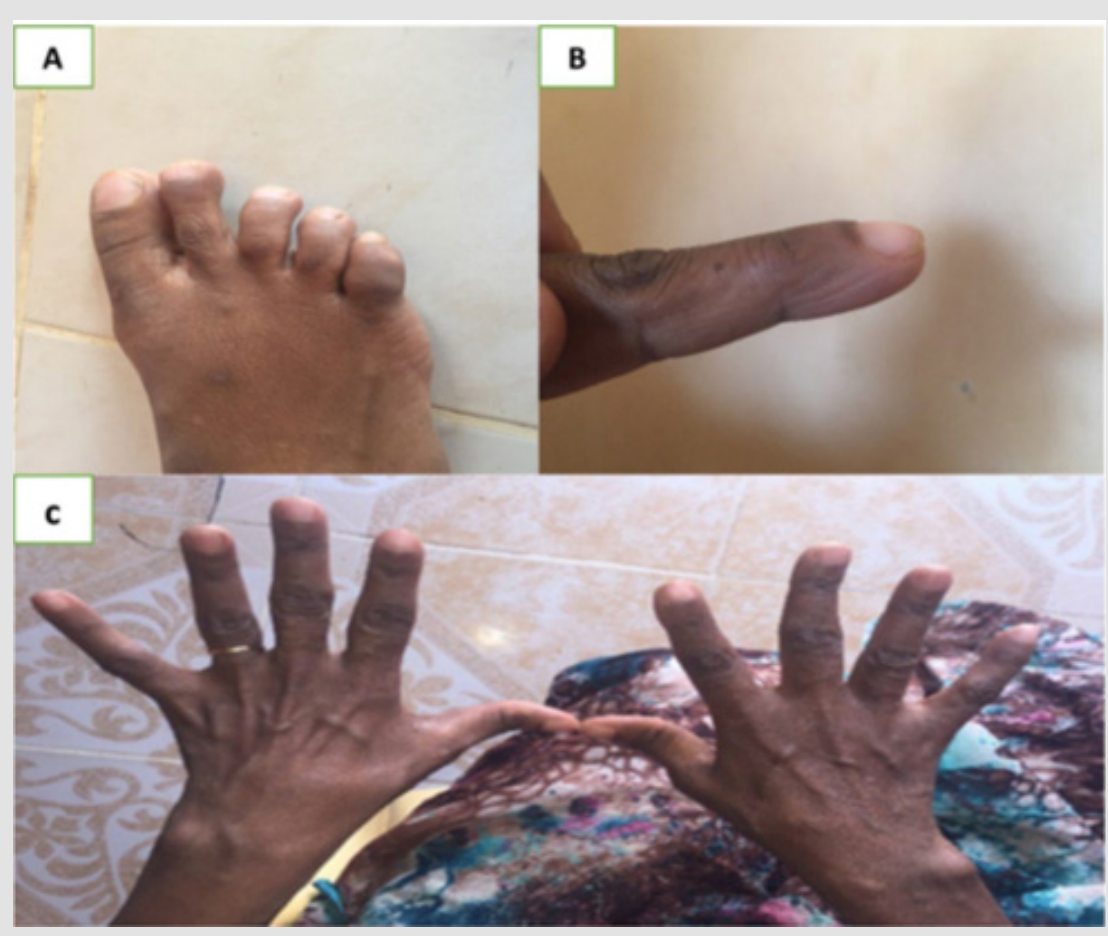

Figure 3: B; Hyper flexed of DIP of both index fingers, C; Z shape deformity of both thumb.

Table 1: Lab Investigations.

\begin{tabular}{|c|c|c|}
\hline Investigation & Result & Normal range \\
\hline White Blood Cells & $8.8 \times 10^{9} / \mathrm{l}$ & $4-11 \times 10^{9} / \mathrm{l}$ \\
\hline Hemoglobin & $10.2 \mathrm{~g} / \mathrm{dl}$ & $12-16 \mathrm{~g} / \mathrm{dl}$ \\
\hline Mean corpuscular volume (MCV) & $73.5 \mathrm{FL}$ & $80-95 \mathrm{fL}$ \\
\hline mean corpuscular hemoglobin (MCH) & $21.2 \mathrm{PG}$ & 27 to $33 \mathrm{pg}$ \\
\hline PLATLET & 468 & $150-450$ \\
\hline Erythrocyte Sedimentation Rate (ESR) & $90 \mathrm{~mm} \backslash \mathrm{HR}$ & Up to $20 \mathrm{~mm} \backslash \mathrm{HR}$ \\
\hline
\end{tabular}




\begin{tabular}{|c|c|c|}
\hline Thyroid-stimulating hormone & 2.16 & $.3-4.2$ \\
\hline $\mathrm{T} 3$ & 1.43 & $1.3-3.1$ \\
\hline $\mathrm{T} 4$ & $2.16 \mathrm{mmol}$ & $.3-4.2 \mathrm{mmol}$ \\
\hline ANA GLOBAL IF & $\begin{array}{c}\text { Fine speculated pattern }+ \text { cytoplasmic granules } \\
\text { Titer } 1 / 1000\end{array}$ & \\
\hline ANA profile & Negative for all items & \\
\hline Rheumatoid factor IGM & 391 & $>20$ positive \\
\hline Anti CCP & Highly positive & \\
\hline VIT D & 9.3 & 20-50 Nanogram \milliliters \\
\hline
\end{tabular}

\section{Discussion}

Rheumatoid arthritis has a strong association with a lot of pulmonary conditions, such as Tuberculosis, pleural effusions, bronchiolitis and BR [6]. The association of RA and BR has been recognized earlier, with the first published report in 1960 [7]. Bronchiectasis is a long-term condition that is characterized by permanent bronchial dilation [8]. The presented patient endure the clinical features of the disease such as sputum production, cough and repeated infections, In addition, CT chest done to the patient showed bilateral septal thickening and ground-glass opacity mild bronchiectasis changes (Figure 1), high resolution CT scan of the chest is considered as the gold standard for confirmation of bronchiectasis [9]. forced vital capacity [FVC], lung function test, sputum bacteriological culture and chest radiograph can also be needed to establish a proper diagnosis [10].Others differential respiratory illnesses such as TB has been laboratory excluded.

The association between BR and RA has not clearly been suggested, the defining cause of the complication is not clearly known [11]. Some reports speculated that RA or its therapy may increase the risk of respiratory infection, leading to BR, Although, the onset of BR often precedes RA as in our presented case [12]. Rheumatoid arthritis is a disease of progressive inflammatory course ended with disability, pain, and sometimes mortality [13]. RA clinically presented with tenderness Involvement of small joints associated with swelling in a symmetrical pattern and abnormal value of autoantibodies such (anti-CCP), rheumatoid factor (RF) and high ESR [14]. The presented case is a classical presentation of RA as it complains of multiple joints pain including hands at metacarpophalangeal (MCP) joints, proximal interphalangeal (PIP) joints, Wrist joints, elbow joints, upper neck and lower back, knees and feet joints. The Patient also showed Tender MIP, PID, Z-shape thumbs appearance, The laboratory investigations revealed high ESR with rheumatoid factor IGM positive with anti-CCP positive (Table 1).

The patient lab works show low level of Vitamin D (low serum 25-hydroxyvitamin D (250HD), as many other reports have linked this condition to RA as a risk factor, however, the causal role for Vitamin D in RA is yet unclear, with conflicting data from many previous reports [15].

\section{Conclusion}

A Sudanese female, presented with multiple joints pain and chronic cough, chest CT scan revealed a presence of BR, more clinical and lab results confirm a diagnosis of RA in the presence of BR. The Patient received hydroxychloroquine, Mycophenolate mofitel acid, calcium supplements,Vitamin D, symbicort inhaler and Vitaferrol Cap (iron tonics). Now patient is in well condition. The case was diagnosed and treated by Dr Ziryab Imad Taha, Rheumatology department at Haj alsafi teaching hospital, Bahri, Khartoum, Sudan and Dr. Asma Elhaj Ibrahim Abdulgadir, Respiratory Medicine department at Alshaab Teaching hospital, Khartoum, Sudan.

\section{References}

1. Acharya S, Mahajan SN, Shukla S, Diwan SK, Banode P, et al. (2010) Rheumatoid interstitial lung disease presenting as cor pulmonale. Lung India 27(4): 256-259.

2. Turesson C, Matteson EL (2004) Management of extra-articular disease manifestations in rheumatoid arthritis. Curr Opin Rheumatol 16(3): 206-211.

3. Cronstein BN (2007) Interleukin-6--a key mediator of systemic and local symptoms in rheumatoid arthritis. Bull NYU Hosp Jt Dis 65 Suppl 1: S1115.

4. Anaya JM, Diethelm L, Ortiz LA, Gutierrez M, Citera G, et al. (1995) Pulmonary involvement in rheumatoid arthritis. Semin Arthritis Rheum 24(4): 242-254

5. Musameh K, Campbell CD (2019) Rutherford RM. Marked deterioration in rheumatoid arthritis associated bronchiectasis following treatment with Rituximab. Respir Med Case Rep 28: 100904.

6. Juge PA, Crestani B, Dieude P (2020) Recent advances in rheumatoid arthritis-associated interstitial lung disease. Curr Opin Pulm Med 26(5): 477-486.

7. Edge JR, Rickards AG (1957) Rheumatoid arthritis with lung lesions. Thorax 12(4): 352-357.

8. Gudmundsson G, Juliusson G (2020) [Bronchiectasis - a review]. Laeknabladid 106(7): 352-361.

9. Wu FJ, Qi Q Hu Q Xu LS (2019) Correlation between chest CT features and clinical characteristics of patients with bronchiectasis. Zhonghua yi xue za zhi 99(38): 2982-2988.

10. Amaral RH, Schuler Nin C, de Souza VV, Marchiori E, Hochhegger B (2015) Computed tomography in the diagnosis of bronchiectasis. The European Respiratory Journal 46(2): 576-577.

11. Takanami I, Imamuma T, Yamamoto Y, Yamamoto T, Kodaira S (1995) Bronchiectasis complicating rheumatoid arthritis. Respiratory Medicine 89(6): 453-454. 
12. Yunt ZX, Solomon JJ (2015) Lung disease in rheumatoid arthritis Rheumatic diseases clinics of North America 41(2): 225-236.

13. Ibraheim MK, Govindu RR (2020) Rheumatoid Arthritis-Associated Interstitial Lung Disease. The American journal of the medical sciences 359(5): 312-313.

\section{ISSN: 2574-1241}

DOI: 10.26717/BJSTR.2021.33.005394

Mohammed Elmujtba Adam Essa. Biomed J Sci \& Tech Res

(C) This work is licensed under Creative

Submission Link: https://biomedres.us/submit-manuscript.php
14. Heidari B (2011) Rheumatoid Arthritis: Early diagnosis and treatment outcomes. Caspian journal of internal medicine 2(1): 161-170.

15. Harrison SR, Jutley G, Li D, Sahbudin I, Filer A, et al. (2020) Vitamin D and early rheumatoid arthritis. BMC rheumatology $4: 38$.

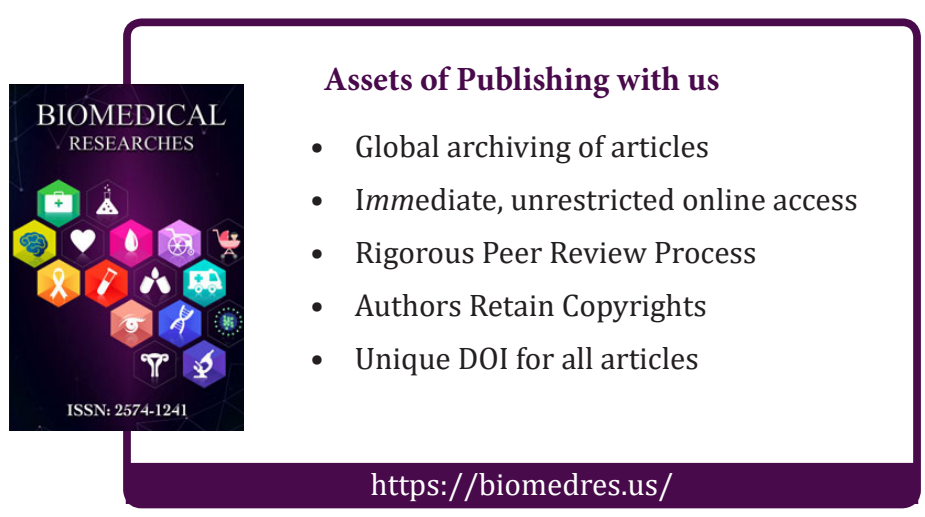

